\title{
An Ethnomathematical Perspective of STEM Education in a Glocalized World
}

\author{
Uma Perspectiva Etnomatemática para a Educação STEM em um Mundo \\ Glocalizado
}

\author{
Milton Rosa* \\ ORCID iD 0000-0002-5190-3862 \\ Daniel Clark Orey ${ }^{* *}$ \\ ORCID iD 0000-0002-8567-034X
}

\begin{abstract}
An Ethnomathematics-based curriculum helps students demonstrate consistent mathematical processes as they reason, solve problems, communicate ideas, and choose appropriate representations through the development of daily mathematical practices. As well, it recognizes connections with Science, Technology, Engineering, and Mathematics (STEM) disciplines. Our pedagogical work, in relation to STEM Education, is based on the Trivium Curriculum for mathematics and ethnomodelling, which provides communicative, analytical, material, and technological tools to the development of emic, etic, and dialogic approaches that are necessary for the elaboration of the school curricula. STEM Education facilitates pedagogical action that connects ethnomathematics; mathematical modelling, problem-solving, critical judgment, and making sense of mathematical and non-mathematical environments, which involves distinct ways of thinking, reasoning, and developing mathematical knowledge in distinct sociocultural contexts. The ethnomathematical perspective for STEM Education proposed here provides a transformative pedagogy that exposes its power to transform students into critical and reflective citizens in order to enable them to transform society in a glocalized world.
\end{abstract}

Keywords: Ethnomathematics. Ethnomodelling. Pedagogical Action. STEM Education. Trivium Curriculum.

\section{Resumo}

Um currículo baseado na etnomatemática auxilia os alunos a evidenciarem processos matemáticos consistentes à medida que raciocinam, resolvem problemas, comunicam ideias e escolhem representações apropriadas por meio do desenvolvimento de práticas matemáticas cotidianas. Além disso, esse currículo reconhece as conexões com as disciplinas STEM (Ciências, Tecnologia, Engenharia e Matemática). Nosso trabalho pedagógico, em relação à Educação STEM, se baseia no Currículo Trivium para Matemática e na Etnomodelagem, que fornece os instrumentos comunicativos, analíticos, materiais e tecnológicos para o desenvolvimento das abordagens êmica, ética e dialógica, que são necessárias para a elaboração de currículos escolares. A Educação STEM propõe ações pedagógicas que se conectam com a etnomatemática; a modelagem, a resolução de problemas, o julgamento crítico e a compreensão de ambientes matemáticos e não-matemáticos, que envolvem as maneiras distintas de pensar, raciocinar e desenvolver os conhecimentos matemáticos em contextos socioculturais distintos. Essa perspectiva etnomatemática para a Educação STEM propõe uma pedagogia transformadora, que expõe o seu

\footnotetext{
* Doctor in Education in Educational Leadership - California State University (CSUS). Professor at Universidade Federal de Ouro Preto (UFOP), Ouro Preto, Minas Gerais, Brazil. E-mail: milton.rosa@ufop.edu.br.

** Doctor in Education - Multicultural Education - University of New Mexico (UNM). Professor at Universidade Federal de Ouro Preto (UFOP), Ouro Preto, Minas Gerais, Brazil. E-mail: oreydc@ufop.edu.br.
} 
poder de transformar os estudantes em cidadãos críticos e reflexivos, visando capacitá-los a influenciarem a sociedade em um mundo glocalizado.

Palavras-chave: Etnomatemática. Etnomodelagem. Ação Pedagógica. Educação STEM. Currículo Trivium.

\section{Initial Considerations}

The complexities of a glocalized ${ }^{l}$ world require individuals equipped with enhanced sets of core knowledge and abilities that enables them to solve problems as well to gather and evaluate evidence that empowers them to make sense of information gained and accumulated from diverse media sources in order to develop their decision-making processes. This context enables members of distinct cultural groups to develop their own ability to adapt new ideas and influences that naturally fit into and enrich these cultures (ROSA; OREY, 2017a). At the same time there is a certain resistance to the absorption of cultural traits ${ }^{2}$ that are alien and/or destructive to their own cultures.

In terms of mathematics education, a glocalized world enables the development of active, interactional, and dialogical processes that requires an ongoing negotiation between the local and the global mathematical, scientific, technological, and engineering knowledge through the development of a cultural dynamism (ROSA; OREY, 2016b). These interacting forms of knowledge evolve a sense of collaboration, cooperation, and communication, which are related to real-world problem-solving, inquiry, creativity, and critical and reflective thinking (STEPHENSON, 2012).

Effectiveness in a glocalized world requires that members of distinct cultural groups develop knowledge and abilities related to their sociocultural contexts in order to: a) both analyze and synthesize information, b) collaborate and respect other people's thinking, and c) use technology effectively, to adequately communicate, and take ownership of their own learning (ROSA; OREY, 2017a). Therefore, schools must be prepared to encourage and support educators in developing their teaching and learning process in new and different ways (GLOVER, 2013).

\footnotetext{
${ }^{1}$ Glocalization is the ability of a culture, when it encounters other cultures, to absorb influences that naturally fit into and can enrich that culture, to resist those things that are truly alien and to compartmentalize those things that, while different can nevertheless be enjoyed and celebrated as different (ROSA; OREY, 2016a).

2 A cultural trait as a system of knowledge consists of patterns of traditions, meanings, beliefs, values, actions, experiences, attitudes, hierarchies, religions, notions of time, norms, roles, spatial relations, concepts of the universe, cosmovisions, cosmologies, artifacts, mentifacts, sociofacts, and symbols acquired by a group of people, which are passed on from one generation to the next and are shared to varying degrees by interacting members of distinct cultural groups (TING-TOOMEY; CHUNG, 2005).
} 
Similarly, Gates and Mirkin (2012) recommend that active learning and discoverybased research coupled with rigorous mathematics instruction is needed to prepare students to live in contemporary societies. According to Lantz (2009), these students are described as problem-solvers, innovators, inventors, self-reliant learners, logical thinkers, and technologically savvy. In today's technology-driven society, there are demands in which members of distinct cultural groups are able to solve problems faced in their daily lives through the processes of investigation, model building, data analysis, presentation of evidence-based reasoning, and communication of findings (MOON; SINGER, 2012).

This context enables the development of the exploration and discovery process, which is connected to the worldwide movement in STEM (Science, Technology, Engineering, and Mathematics) Education. This process contributes to the development of these skills by enabling members of distinct cultural groups to learn how to take team-based approaches to tackling ongoing challenges faced in different contexts. Thus, members who are glocally competent develop abilities that enable them to function in an interdependent and diverse glocalized world and to communicate with respect to other cultures.

Consequently, a glocal world breaks down the barrier of distance, which allows for a continuous interaction within both local and global communities. In this context, all communities "need citizens who can lead global [and local] efforts to reduce distrust and fear among different people" (ZHAO, 2010, p. 155) through a transformative form of education that provides a voice for the members of these communities by raising their consciousness and advancing an agenda for change to improve their lives.

This approach becomes a united voice for reform and change. Advocates for this kind of pedagogy favor actions that develop student-centered methodologies, which emphasize innovation, problem-solving, critical thinking, reflective reasoning, and creativity. These methods are related to the development of a project-based learning that enables students to use, interact, collaborate, and work on real or authentic situations, problem-solving techniques, as they learn to become creative and to target real-world problems to solve (WILLINGHAM, 2009).

A focus on creativity and innovation is necessary for innovative ways of learning to emerge. Hence, "engaging students in work that results in their need to learn material that is essential to their education as citizens in a democracy and to their right to claim to be well educated human beings is the primary business of schools" (SCHLECHTY, 2011, p. 8). This approach emphasizes social justice and student empowerment through mathematics education that is important for the development of society and democracy. In this context, mathematics 
education can play an important role in developing critical and reflective citizenship (ANDERSSON; NORÉN, 2011).

This kind of effective instruction actively engages students in science, mathematics, and technological practices throughout their school (NRC, 2014) that provides them "with opportunities to learn science and engineering by addressing problems that have real-world applications" (CHIU; PRICE; OVRAHIM, 2015, p. 7). This perspective is related to STEM disciplines that help students to foster their inquiry skills and creative, critical, and reflective thinking, collaboration, and communication. For example, Bybee (2010) affirmed that STEM also includes other domains such as Language Arts, Social Studies, and the Arts.

According to the National Research Council (NRC, 2014), the development of and interaction with these disciplines help students to interact and engage with the members of their own communities as well to work on innovation, collaboration, and inquiry. This approach allows students to develop powerful analytical skills by addressing a diversity of ways that allow them to see, perceive, and experience their own world. In order to reach this goal, STEM students are taught through constructivist methods aimed at building content understanding and application of knowledge.

This context enables students to become conscious citizens who apply knowledge in meaningful ways, and who are encouraged to address issues that improve the lives of their community members (STEPHENSON, 2012). STEM Education aims to build content understanding and application of knowledge (LANTZ, 2009), which is developed through the expansion of learning environments that support the acquisition of life-long knowledge (ROTHERHAM; WILLINGHAM, 2009). This perspective helps members of distinct cultural groups to "develop the skills, attitudes, and habits of mind necessary to be productive in today's society" (SCHLECHTY, 2011, p. 120).

Currently, STEM education programs are becoming increasingly recognized as key drivers for the development of sociocultural opportunities that are fundamental components of a comprehensive education for all students. It is a meta-disciplinary approach defined as "the creation of a discipline based on the integration of other disciplinary knowledge into a new "whole" (LANTZ, 2009, p. 1). It promotes the advancement of school curricula in an interdisciplinary approach that seeks to enhance learning by promoting both local and global innovations developed in distinct sociocultural contexts (ROSA; OREY, 2017b).

Hence, rather than teaching science, technology, engineering, and mathematics as separate and distinct subjects, STEM integrates them into a cohesive and holistic educational paradigm (ELAINE, 2014). STEM education enables students to develop knowledge, 
attitudes, and abilities that allow them to identify questions taken from real-life situations and then, draw evidence-based conclusions about these problems. This approach encourages a deeper understanding of science, technology, engineering, and mathematics as forms of human knowledge related to their glocal community (BYBEE, 2010).

STEM education also involves the integration of these subjects by breaking down compartmented disciplines with the objective of making connections to their daily lives (NRC, 2014). On the other hand, traditional curriculum and evaluation standards remain in place, which impedes the ability of educators to freely identify, explore, and expand connections between these knowledge traditions. Thus, it is necessary to mention that STEM education is a topic of great interest in public policy and has become an international topic of discussion (ROSA; OREY, 2017a).

Students that have access to practical and relevant STEM experiences can play an important role in their own communities as empowered and transformative citizens. For example, Bybee (2010) states that educators must be aware of how STEM disciplines are shaped by the material, intellectual, social, technological, and cultural environments. This awareness helps students to become constructive, critical, and reflective citizens through engagement in STEM-related issues.

Since the development of and adherence to STEM teaching and learning practices is not widespread in the school curricula, especially here in Brazil, opportunity gaps persist. In this regard, Marginson et al. (2013) affirm that there is a growing demand for STEM Education to meet the diverse needs and the demands of distinct sectors of contemporary society. This context enables STEM to become increasingly recognized as a key driver of educational opportunities for all, especially for the development of members in distinct cultural groups.

However, Rosa and Orey (2017a) state that the abilities developed by STEM are far from meeting these demands as, frequently, its experiences lack connections to social class, racial, ethnic, cultural, and gender diversity that are required to address technological, mathematical, engineering, and scientific needs of a glocalized world. It is also important to point out that there is insufficient STEM literature accounting for the unique political, social, cultural, environmental, and economic realities, and backgrounds of students in non-western contexts, yet its principles have become an essential part of the solution in the educational system development worldwide.

In this regard, Chubin and Malcom (2008) argue that it is necessary to further articulate a true sense of STEM diversity that enhances complex thought development by 
allowing students to learn how to solve scientific and mathematical problems in innovative ways. This context allows STEM Education to be a major thematic domain in many countries in which there is a demand for qualified investigators, educators, scholars, and technicians. For example, expected international economic growth requires a workforce for developing the world economy, which at the same time lacks the necessary skills and abilities that further allow its population to participate in an increasingly competitive global economy.

The main objective of this theoretical article is to ascertain diverse pedagogical actions that enable educators and students to use local mathematical knowledge in the development and reconceptualization of STEM Education related to mathematics curriculum in order to help students to demonstrate consistent mathematical processes as they reason, solve problems, communicate ideas, and choose appropriate representations through the development of daily mathematical practices.

As well, another objective is to explore possible connections between ethnomathematics and STEM education grounded on the trivium curriculum and ethnomodelling, which provides communicative, analytical, material, and technological tools to the development of emic, etic, and dialogic approaches that are necessary for the elaboration of the mathematics curriculum. In this regard, STEM education facilitates a sense of pedagogical action that connects ethnomathematics; mathematical modelling, problemsolving, critical judgment, and making sense of mathematical and non-mathematical environments, which involves distinct ways of thinking, reasoning, and developing mathematical knowledge in distinct sociocultural contexts.

It is important to emphasize that ethnomathematical perspectives in STEM education proposed in this article provides a transformative pedagogy that exposes its power to transform students into critically reflective citizens in order to enable them to transform society in a glocalized world. This approach offers one way to apply local mathematical ideas, procedures, and techniques to help students to develop innovative technological resources to solve problems they face daily in their own communities.

\section{Proposing a Pedagogical Action for a STEM Education Program based on Ethnomathematics}

There is a need for STEM programs to encourage investigators and educators to identify diverse learning-teaching practices and pedagogical actions that allow the development of activities based on ethnomathematical perspectives. It is important to state 
here that a relevant goal of STEM is to support students to develop abilities such as collaboration, communication, problem solving, and inquiry for their success in a glocalized world. The assumption that science, mathematics, technology, and engineering experiences should be available only to individuals who are naturally gifted in these subjects creates obstacles to innovative approaches to teaching and learning processes that benefit all students.

Any view of school education perpetuates deterministic views of genetics or stereotypic ideas of culture and fails to recognize its benefit in promoting higher level critical thinking skills and lifelong civic engagement (VOLMERT et al., 2013). In this regard, teachers must be involved in and encouraged to develop the understanding and interests of all their students in order to engage them in their learning process (GLOVER, 2013). In this context, students need opportunities and encouragement in mathematics classrooms that enable them to build bridges between their own cultural and school contexts, which can be enhanced though the development of project-based methodologies (OREY; ROSA, 2018).

These projects provide contexts that generate both need and possibility for educators to organize mathematical content in a way that gives meaning in accordance to themes they choose to develop in classrooms. This enables learners to develop their own projects by involving issues relevant to their communities, such as consumer education that allows them to study mathematical content related to percentage, interest, and the monetary system (OREY; ROSA, 2018).

Project-based methods are instructional methodologies that include challenging questions or phenomena involving students' problem-solving, decision-making, and investigative abilities. There is also a critical reflection component that involves teachers as facilitators of this process. These projects integrate the knowing and doing in order to support the notion that students construct their own learning by driving questions that encourage them to discover central concepts and principles of mathematical and scientific concepts through hands-on learning (MARKHAM, 2011).

Therefore, through STEM education, students work with project-based methods that aim to build content contexts and understanding through interdisciplinary applications (LANTZ, 2009). This process enables the development of creative and critical thinking as well as testing for and practicing reflective reasoning. There is a necessity for support for educators to learn to diversify their practice and learning methods that promote opportunities for culturally relevant pedagogies that encourage the enabling of innovative modes that explore STEM concepts in the classrooms (D'AMBROSIO, 2016). 
These flexible learning environments invite the development of realistic, creative, and experimentative simulations, which are accessible and unintimidating educational experiences (ROSA; OREY, 2017a). For example, it is necessary that educational leadership initiatives and accompanying policies are associated with STEM in order to provide opportunities to all members of distinct cultural groups in the schools' communities and service areas that propitiate technical, technological, and engineering oriented pedagogies, relevant to the sociocultural context of their students (OREY; ROSA, 2018).

In this regard, STEM cultural practices need to be recovered and integrated into mathematical curriculum in order to help educators to develop pedagogical-based activities through an ethnomathematical perspective (FURUTO, 2014). For example, ethnomathematics deals with the unique culture, historical tradition, sociocultural roots, and mathematics of the school community by encouraging investigation and adaptation of these concepts both within and outside of the classroom (D'AMBROSIO, 2006).

For example, STEM must include local applications with a cultural basis in the curricular activities across all grade levels in both formal and informal settings (GONZALEZ; KUENZI, 2012). According to this point of view, VOLMERT et al. (2013) argue that mathematics learning must reach beyond the school walls in order to include its connections to local contexts.

From an ethnomathematical perspective, it is important that STEM disciplines are connected to the local, historical, social, cultural, political, environmental, and economic context of participants in order to allow learners to perceive the holistic and lifelong nature of learning with experimental experiences that occur outside of the classrooms (D'AMBROSIO, 2016). Therefore, educators and students must be supported to incorporate teaching and learning experiences from both within and outside of school, because the more real, familiar and humanized STEM disciplines become to learners, the more likely they are to picture themselves in these fields (ROSA; OREY, 2017a).

Ethnomathematics focuses on the epistemology, philosophy, history, science, and mathematics with pedagogical implications for education (D’AMBROSIO, 1999). This perspective encourages the investigation and adaptation of these disciplines within formal and informal environments through the development of physical, environmental, spiritual, social, and cultural capacities. For example, many people across the planet make and use canoes in response to their own needs to travel and to transport food on water in order to survive and transcend (ROSA; OREY, 2017a). 
This perspective deals with ancestral engineering concepts that are related to the construction and navigation of canoes because it gives evidence and support for the incorporation of STEM elements into the mathematics curriculum. This approach helps the development of cultural understanding regarding the process of studying canoe construction by members of distinct cultural groups. For example, Fritz, Strong, and Bryant (2007, p. 3) state that "if one wishes to study another culture and civilization, it is necessary to study its engineering as a cultural activity".

It is also relevant to state here that a "key element is to establish engineering as a cultural activity, and to recognize the differences in practice between cultures" (FRITZ; STRONG; BRYANT, 2007, p. 3). Thus, this context enables the acknowledgement of local and ancestral engineering that are also found in the construction of hemispherical lodges (SHOCKEY; MITCHELL, 2017) and tipis (OREY, 2000). Figures 1 and 2 respectively show ancestral engineering placements found in a hemispherical lodge and a conical tipi dwelling.

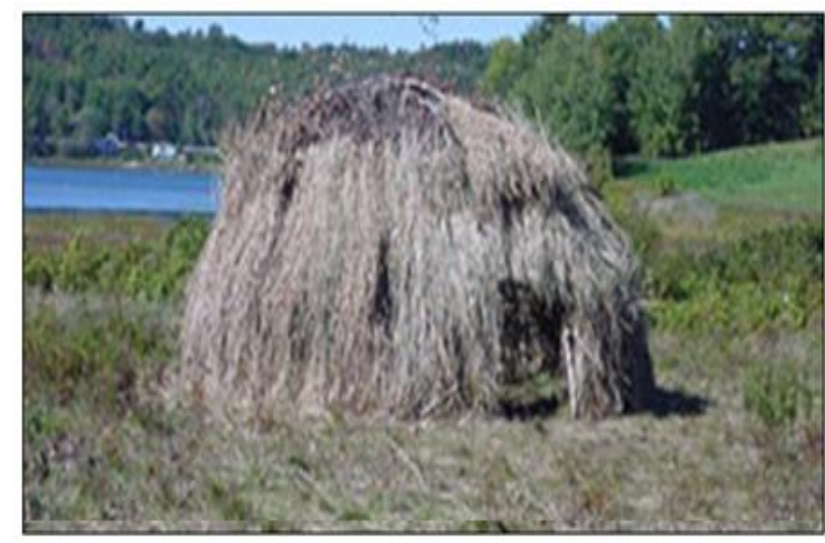

Figure 1: Ancestral engineering of a hemispherical lodge Source: Shockey (2017, p. 275)

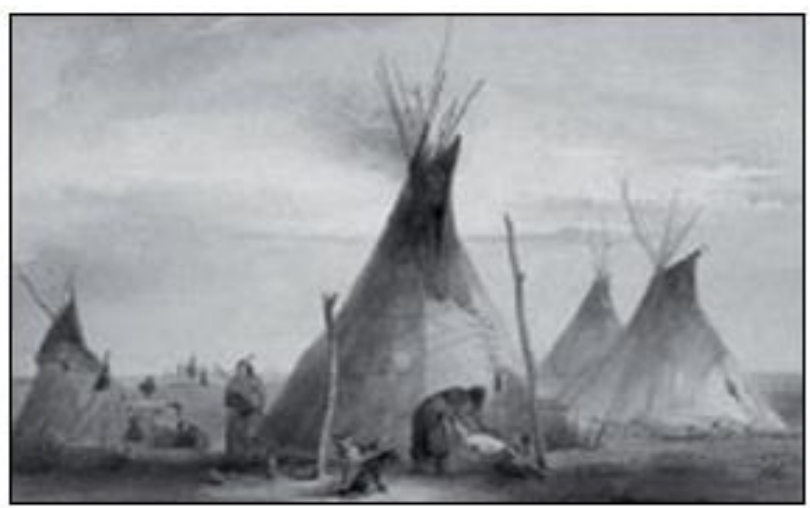

Figure 2: Ancestral engineering of Sioux tipi conical tent dwelling Source: Rosa and Orey (2017b, p. 63)

In relation to the hemispherical lodge construction, Shockey and Mitchel (2017, p. 275) argue that: 
The practical application of ethnomathematics and the development of an ethnomodel ${ }^{3}$ of this lodge can be a conduit for children to engage in western mathematics. The youngster that used her arm to make sure parallel placement of the tensile strengthening poles occurred is an example of how a student may engage. Considering the Ancestral Engineering (...) perspective that (...) was brought to this construction, it is rich in relationships. (...). Lodges were typically built based on location using available materials. The time of year determined what materials were available. These cultural perspectives for time of year and what materials are available are elements of the ethnomodel for this lodge.

Corroborating with this assertion, Fritz, Strong, and Bryant (2007, p. 3) affirm that "concepts of design which encompass the ideas of minimizing resource consumption, return of the resources to the environment, and minimizing the impact on the planet, will be critical to future engineering practice", which is one of the main objectives of STEM education. According to this context, it is necessary to revisit a previous investigation conducted by Orey (2000), which was developed in relation to the elaboration of ethnomodels related to tipis in which plane and spatial geometrical concepts are inherent to the shape of this tent.

For example, for the Sioux First Nations People withstand the harsh reality of life on the plains, they adapted a tripodal foundation to build their tipi homes because it offered more resistance to harsh weather than a base formed by a quadripodal foundation. Throughout history, most residents of tipis realized that the tripod foundation was the best defense against prevalent and often heavy winds of the open prairies in North America (ROSA; OREY, 2017b).

This context enabled Laubin and Laubin (1989) to discuss both scientific and historical evidence in which a tripod foundation is the most common structure in areas that have fewer natural obstacles and are thus more prone to wind. Furthermore, for the tipi to have better stability, the tripod foundation itself employed the approximate shape of an equilateral triangle. The traditional tipi also had the advantage of providing a stable structure that was both lightweight and portable, and which allowed members of this distinct cultural group to move in the plains (OREY, 2000).

For example, an ethnomodel explains why a tripod is more resistant and stable than a quadripodal structure by applying the unique plane assumption, which states that through

\footnotetext{
${ }^{3}$ Ethnomodels are defined as cultural artifacts that are the pedagogical tools used to facilitate the understanding and comprehension of systems taken from the reality of members of distinct cultural groups. They are considered representations of local phenomena and are precise and consistent with the scientific and mathematical knowledge socially constructed and shared by these members. The main objective for the elaboration of an ethnomodel is to translate mathematical ideas, procedures, and practices developed by these members into other mathematical knowledge systems, including school mathematics. Hence, these members develop ethnomodels that represent systems taken from their own reality in order to help them to understand and comprehend their world by linking aspects of their own cultural heritage with the development of mathematical ideas, procedures, and practices (SHARMA; OREY, 2017).
} 
three non-collinear points, there is exactly one plane (figure 3). This plane-point postulate makes the triangle one of the strongest and most stable geometric figure and, in this case, gives an optimal resistance to wind and harsh weather (OREY, 2000).

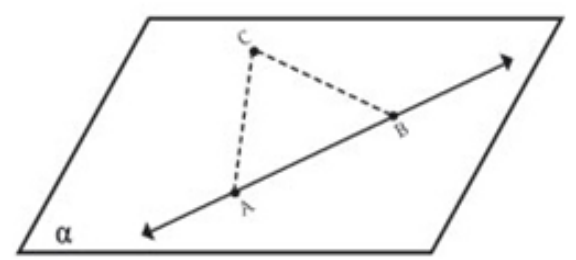

Figure 3: Plane-point postulate

Source: Rosa and Orey (2017b, p. 65)

Regarding the construction of the tipi foundation, this information can be determined mathematically by developing another etic ethnomodel (figure 4).

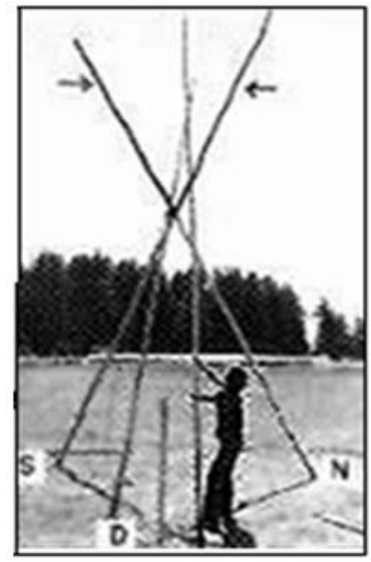

Figure 4: The construction of the tipi Source: Rosa and Orey (2017b, p. 65)

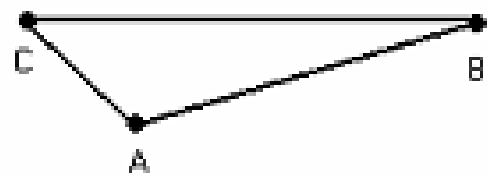

Figure 5: Shows the base of the Tipis formed by the tripod $\triangle \mathrm{ABC}$ Source: Orey (2000, p. 66)

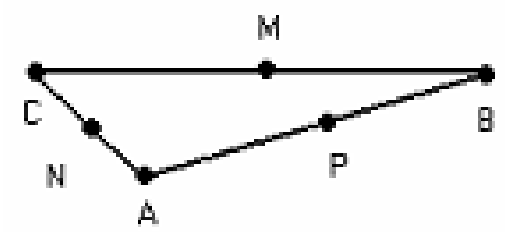

Figure 6: Shows the midpoints of each of the $\triangle \mathrm{ABC}$ sides are points $\mathrm{M}, \mathrm{N}$, and $\mathrm{P}$ Source: Orey (2000, p. 66) 


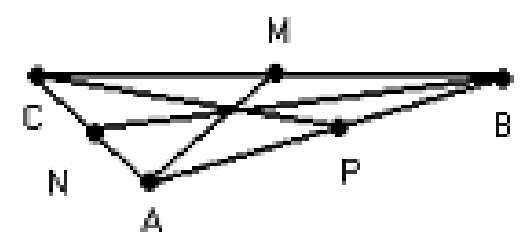

Figure 7: Shows that by matching each vertex of $\triangle \mathrm{ABC}$ to the midpoint of each opposite side gives the line segments $\mathrm{AM}, \mathrm{BN}$, and $\mathrm{CP}$

Source: Orey (2000, p. 67)

These line segments form three medians that connect the midpoints of each opposite side of $\triangle \mathrm{ABC}$ and its vertex. The medians intersect at only one point called centroid of the triangle, which is the point where all the mass of a triangular plate act. It is also known as its center of gravity, center of mass, or barycenter. This triangular base finds a balance at the intersection point of the medians. We emphasize that, historically; Archimedes demonstrated that the medians of a triangle meet at its balance point or gravity center (OREY 2000).

Thus, the results of the study conducted by Orey (2000) showed that the Sioux people understood the distinction between tripodal and the quadripodal foundations because they developed notions related to plane and spatial geometric concepts and, through observation, they passed this information from generation to generation. Figure 8 shows an ethnomodel that relates to the tripodal foundation stability.

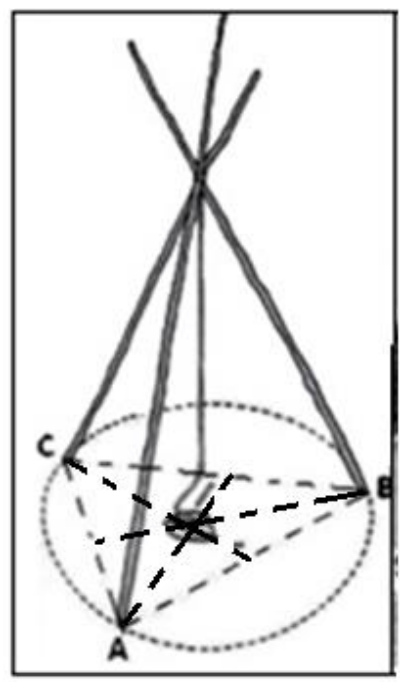

Figure 8: The center of the tipi's circular tripodal base Source: Orey (2000, p. 64)

These ethnomodels demonstrate the emergence of local mathematical knowledge regarding the use of a tripodal base that provides greater stability to its foundation. Figure 8 also shows the center of the circular tripodal base of the tipi tent dweller. The tipi cover is folded in half and the poles are laid together before tying them to construct its tripodal foundation. It is important to emphasize that the Sioux people place and kindle the fire at the tipi center, as well as they use this place to cook, and to heat the tent's interior. 
At this central place (centroid), they also built a holy altar to burn incense during their prayers (OREY 2000). Thus, Rosa and Orey (2017b) state that this central part of the tipi holds an infinite power and holiness, which means more than just need or aesthetics because it enables them to find the sacred center of the Sioux home. According to Fritz, Strong, and Bryant (2007, p. 3), the "spirituality and respect for nature is inherent in Ancestral Engineering".

Hence, the tacit procedures (emic knowledge) used in this mathematical practice have been transmitted to the members of the Sioux people through generations by the women in this cultural group, who are responsible for the instruction, construction, and maintenance of housing. According to D'Ambrosio (2006), mathematical techniques, strategies, and practices are socially learned and historically diffused across generations between the members of diverse cultures.

In this regard, etic approaches dealt with features of school and/or academic mathematics regardless of the cultural group studied and emic approaches looked at, explores, and described systems of emic knowledge of Sioux people on its own terms and by identifying the units and structural classes of this cultural group. Thus, Rosa and Orey (2010) state that the dialogical approach translates procedures used in these mathematical practices for the understanding of those who have different backgrounds so that both can understand and explain this mathematical practice from the emic-etic (dialogical) approach.

On the other hand, Roehrig et al. (2012) argue that it is necessary to propose the reformulation of STEM activities in order to improve mathematics education by developing knowledge based on mathematical modelling (ENGLISH; HUDSON; DAWES, 2013). Furthermore, Rosa and Orey (2017a) affirm that STEM knowledge can be achieved through the development of ethnomathematics, trivium curriculum, ethnomodelling, and ethnocomputing, which contributes to the evolution of this emerging educational field.

For example, ethnomodelling is the study of mathematical ideas and procedures elaborated by members of distinct cultural groups that involve mathematical practices developed, used, practiced, and presented in diverse situations in their daily life. This allows those engaged in this process to study mathematics as a system relative to their own contextual reality in which there is an equal effort to create an understanding of all components of these systems as well the interrelationship among them (ROSA; OREY, 2016b).

This context enabled ethnomodelling to be considered as the translation of local ideas, procedures, and practices in which the prefix ethno is related to the specific mathematical 
knowledge possessed by members of distinct cultural groups. Thus, ethnomodelling adds cultural perspectives to the modelling process by starting with the sociocultural context, reality, and interests of the students and not by enforcing a set of external values and decontextualized curricular activities without meaning for them (ROSA; OREY, 2017c).

Similarly, ethnocomputing helps translating STEM ideas and procedures that are embedded in local cultural practices and vernacular activities to their contemporary equivalents. It is a democratic learning environment in which local knowledge systems are used as cultural educational tools that represent a constructionist pedagogy designed to develop computational capital in culturally relevant ways (EGLASH et al., 2006).

In this perspective, the trivium curriculum supports programs that can enable our students to both meet academic needs and improve their mathematical competencies, abilities, and skills (D'AMBROSIO, 1999). For example, this curriculum develops an important and innovative approach regarding the possibilities of implementing pedagogical action in schools by helping students demonstrate effective mathematics processes as they reason, solve problems, communicate ideas, and choose appropriate mathematical representations that allow them to synthesize procedures and practices developed in their own sociocultural contexts (ROSA; OREY, 2015).

These examples show the importance of ethnomathematics regarding STEM, which is related to the expansion of practical and pedagogical implications in schools, since it proposes the development of curriculum innovation to erase arrogance, inequity, and bigotry in society (D'AMBROSIO, 2016). This approach proposes a transformative pedagogy for STEM because its main objective is to transform students into critical and reflective citizens.

Ethnomathematics most relates to STEM, as it incorporates a holistic and cultural approach into mathematics curriculum and is concerned with mathematical practices found in distinct contexts (ROSA; OREY 2017a). It is also interested in mathematical knowledge that is related to the scientific and technological needs of the members of distinct cultural groups.

In this context, Rosa and Orey (2015) affirm that this approach deals with local mathematical perceptions, ideas, notions, procedures, and practices, as well with the underlying cosmologies developed by members of distinct cultural groups.

Therefore, the "emergence of ethnomathematics, as a research field, is the result of the recognition that every cultural group develops, as a result of its rationality, its own ways and styles of explaining, understanding, and coping with their environment" (D'AMBROSIO, 2006, p. 79). 
Therefore, ethnomathematics can be considered as an alternative proposal for the pedagogical action of the mathematics curriculum because it recognizes the relevance of often very unique cultural dynamics of the encounters when old meets new, which brings attention to the understanding of how mathematical, technological, and scientific ideas are generated throughout history.

For example, Rosa and Orey (2017a) state that mathematics is often considered as the knowledge field produced exclusively by members of western cultural groups, communities, or societies, and it ignores the contributions of diverse members for the development of humanity.

Historically, an ethnomathematics perspective allows individuals to make explicit historical, social, and cultural dynamics and the production of mathematical knowledge developed by the members of distinct cultural groups in distinct contexts. Thus, it is important to discuss opportunities for innovation in order to propel investigations that help educators to develop pedagogical actions that emerge in and from distinct cultural contexts. This approach enables them to better serve diverse students and motivates them to achieving transformative societal changes (ROSA, 2010).

Ethnomathematics has a strong and pivotal role in promoting and achieving STEM education because it is constituted of local scientific, mathematical, and technological perspectives that lead education towards the development of innovative ideas that are better explored from locally sourced educational materials that can build strong and deep connections to school/academic mathematics (ADENEGAN; IPINLAYE; ADEWOYE, 2016). This perspective coupled with ethnomodelling and the trivium curriculum provides communicative, analytic, material, and technological instruments that help students develop and socialize the quantitative and qualitative ways of dealing with their own reality.

According to Rosa and Orey (2017b), this mathematics curriculum offers a platform for incorporating ethnomathematical approaches into STEM education by addressing issues that make both individual and other lives better. Thus, it is necessary to develop inclusive learning environments that offer educators and students flexibility in structure, equipment, and access to materials as well to technological-based platforms that can enhance learners' experiences. 


\section{An Ethnomodelling and Trivium Curriculum for STEM Education based on Ethnomathematics}

The trivium curriculum helps students to recognize connections between mathematical concepts and STEM disciplines by providing communicative, analytical, material, and technological instruments that originate in their own contexts, cultures, and ways of learning in the educational process. The components of this curriculum are literacy (communicative instruments), matheracy (analytical instruments), and technoracy (material and technological instruments) (D’AMBROSIO, 2007).

\section{a) Literacy}

Literacy is related to the use of communicative instruments. It is the critical capability of processing information such as the use of written and spoken language, signs, gestures, and numbers. In this regard, critical reading means to read with the goal of finding deep understanding to comprehend a diversity of informational and communicational materials (D’AMBROSIO, 1999).

From this perspective, the act of reading has a new meaning because along with literature, students need to read and be able to understand instructions for technical-scientific literature and/or school tasks. It also includes the ability to critically interpret data available in newspapers, magazines, books, and social media. They also need to be able to comprehend statements of employee benefits, payment schedules, tax tables, mileage charts, and sports league standings that are depicted in graphics. These sources provide unlimited resources for mathematical information (ROSA; OREY, 2017a).

Thus, literacy involves the interpretation of graphs, tables, charts, diagrams, figures, numbers, signs, and other ways of achieving understanding of the condensed language of codes (D'AMBROSIO, 1999). These elements are related to the communicative instruments that enrich the capability of discourse, conversation, and description. Critical familiarity with, indeed the ability to gain information from and interpret information from these instruments, often embedded in diversified cultural environments, is part of dealing with a Trivium/STEM literacy.

For example, the National Governors Association (NGA, 2011) has defined STEM literacy as the ability that individuals possess to adapt to and to accept changes driven by innovative technologies, to work with others across borders, to anticipate the multilevel 
impact of their actions, to communicate complex ideas to a variety of audiences, and to find measured creative solutions to problems faced by society.

\section{b) Matheracy}

Matheracy provides individuals with the analytical instruments and symbolic analysis of the mathema that enables them to learn, explain, know, and cope with their own environment by developing approaches based on reason and evidence. According to Rosa and Orey (2017a), matheracy comprises the capability for inferring results to reach conclusions based on data or known facts. This relates to the formation of opinions from evidence and moves away from a media-fueled emotion. It is connected to the proposition of testing a hypothesis and the interpretation of information that enables students to draw conclusions from their data.

A broader concept of matheracy relates to an individual's ability to compare, count, measure, cipher, classify, quantify, generalize, infer, and model, all of which aims to explain, understand, and comprehend reality and its phenomena that are the elements of knowledge developed overtime. This set of abilities gives meaning to reading, understanding, comprehending, and interpreting data (D’AMBROSIO, 2007).

Matheracy is also a first step toward an intellectual, critical, and reflective posture in relation to the individuals' engagement to determine solutions for problems faced by society. It is also related to a deeper reflection about humankind and society through the development of the individuals' intellectual posture that helps them fully participate in the community life as a critical and reflective citizen (D’AMBROSIO, 2007).

This approach enables individuals to either defend concrete propositions or denounce injustices, usually, by defending a system of values, which support them to adopt an attitude or take a position on problems that affect their lives (ROSA; OREY, 2017a). Hence, the absence of this posture in a school system, mainly in mathematics classrooms, allows students to only perform mechanical calculations that are unrelated to the activities they perform in their daily lives (D’AMBROSIO, 2007)

Unfortunately, mathematical activities developed in many traditional classrooms can be considered as a set of mechanical or grammatical techniques that enable students to manipulate numbers and operate mathematical rules without being allowed to see a deeper connection to the mathematical power and beauty. This approach ends up impoverishing mathematics instruction by restricting it to purely manipulative techniques and procedures that are solely necessary for utilitarian purposes (D'AMBROSIO, 2007). 
In this context, matheracy is the result of the appropriation of STEM abilities with its notions and concepts acquired through the development of competencies that allow all students to critically analyze data and be able to truly make sense of information available in different types of media such as newspapers, books, magazines, recorded music, film, social networks, radio, television, and the internet.

\section{c) Technoracy}

Technoracy is related to the individuals' familiarity with and use of technological tools and instruments found in computers, software, calculators, and digital equipment into the process of teaching and learning mathematics. While it is important to recognize the universal role of technology, and at the same time its implication for the development of scientific and mathematical knowledge, there is a need to recognize the relevance of the technology history because it is an essential element for furthering ideas, concepts, and theories relating to the development of scientific and mathematical knowledges (D’AMBROSIO, 2006). Thus, it is necessary that students comprehend the importance of using technology, monitoring and following its ongoing renovation (D’AMBROSIO, 1999).

Technoracy also refers to technological resources ranging from simple stone tools to complex genetic engineering and information technology. Thus, this unique mixing of ancient and new knowledge has enabled members of distinct cultural groups to create innovative tools, and conversely, many scientific endeavors are made possible by technologies that assist them in traveling to different places. This technological progress is the primary factor driving the development of humanity (BUCHANAN, 2019).

In this context, a diversity of technologies that sustained humanity for millennia, such as stone adzes, papyrus for writing, sundials, aqueducts, outhouses, telegraph, video cassette recorder, carbon paper, mimeograph, typewriter, cobblestone, and the steam locomotive, are being surpassed by electronic tools, often without discussion or realization for what they are replacing (ROSA; OREY, 2017b).

In this regard, D'Ambrosio (2012) states that the rapid development of technology has allowed for the acceleration and dissemination of the acquisition of mathematical concepts, procedures, and techniques that are necessary to solve problems faced in daily life. For example, some students have access to the internet and can obtain a wider variety of information, often without discussing their relevance, necessity, or its value.

There are connections between old or traditional and modern technological tools. With a cumulative and a progressive element to technology development because the strategies are 
unique, in which each generation inherits a stock of techniques on which it can build if it chooses and if social conditions permit (BUCHANAN, 2019). The implementation of cellphones and smartphones worldwide is an excellent example of this. Over a long period of time the history of technology acquisition and adoption inevitably highlights the moments of innovation that show this cumulative quality as some societies advance, stage by stage, from comparatively primitive to more sophisticated techniques.

The history of humanity also shows its connections to technology and mathematical thinking from the: a) use of simple aide-memoires for counting and arithmetic in weaving, b) constructions of buildings, c) elaboration of trade routes, d) introduction of calculus to solve technological problems faced by societies; and e) use of computers to solve both technological and mathematical problems (BUCHANAN, 2019; HANSSON, 2019).

For example, one of the earliest uses of mathematics was involved in the crafts of weaving and drum construction. In this context, advanced hand-weaving traditions have arisen in all parts of the world, as demonstrated by the complex weaving techniques developed by members of many cultures, often geometrical patterns with intricate symmetries (HANSSON, 2019). These technological resources were informed by patterns from the past that transformed into current roles of advanced technologies that promoted the development of mathematical thinking and education (PEA, 1986).

Because members of distinct cultural groups use different technologies and languages, beyond oral and written communication, which installs new production of rhythms, rapid assimilation of information, and proposing and solving problems collaboratively and cooperatively, this approach allows for the development of a sense of criticality and the development of innovative competencies, abilities, and skills required for the use of diverse knowledge systems.

It is important to offer a practical alternative methodology for research, which includes the acquisition of a STEM-based criticality by making use of both emic and etic knowledge traditions. Emic knowledge is essential for an intuitive and empathic understanding of mathematical ideas of a culture. It is essential for conducting effective ethnographic fieldwork. Etic knowledge is essential for cross-cultural comparisons that demand standard units and categories to facilitate communication and collaboration (ROSA; OREY, 2017b).

An approach that uses a STEM/Trivium mathematics curriculum applies both emic and etic knowledge traditions through processes of dialogue and interaction developed in ethnomodelling, which is defined as the study of mathematical phenomena within a culture because it is a social construct and culturally bound that also deals with ethnomathematics and 
STEM principles (ROSA; OREY, 2017b). It is important to state here that the same approaches of dialogue and interactions are also evident in technology development throughout history.

Local (emic) and global (etic) communities are equally exposed to social and popular media outlets that focus on STEM and its wide diversity of themes that help empower members of distinct cultural groups to understand, comprehend, transform, and shape the world. It also offers educational instruments that enable all students to restore cultural identity, dignity, and develop citizenship (ROSA; OREY, 2015).

For example, the results of the study conducted by Cortes and Orey (2020) showed how dialogic approaches of ethnomodelling contributed to the process of re-signification of function concepts learned by 38 students in the second year of high school during their interaction with a local farmer and his labor practices. This approach enabled students to understand the importance of cultural conceptions and elaboration of ethnomodels extracted from the mathematical practices developed by the farmer for use as a pedagogical action in the classrooms.

These results also showed that ethnomodelling provides an integrative approach to school mathematics curriculum by considering both the emic and etic mathematical knowledge through the development of a dialogic approach that shows the relevance of its cultural dynamism, which are related to the concepts of the trivium curriculum and STEM education.

It is important to state here that ethnomodelling assists the development of the ongoing educational reconstruction process that seeks to relate school mathematics with the elaboration of curricular activities developed by the members of distinct cultures by using their own sociocultural elements, such as:

a) Artifacts as observational instruments created and developed by the members of distinct cultural groups that provide clues and information about its creators and users.

b) Mentifacts as analytical tools such as thoughts, reflections, concepts, and theories that represent the ideas and beliefs of the members of a particular cultural group, such as religion, language, and laws.

c) Sociofacts represent the social constitution of the members of distinct cultural groups such as family and tribal structures. These sociocultural elements can be considered as patterns of interpersonal relations expected and accepted among members of these groups, which help us understand the effects of colonization, prejudice, inequity, and harm due to the disconnections between knowledge as practiced in the academy and its practical use in everyday life (D'AMBROSIO, 2018, p. 202).

In accordance with this assertion, it is necessary that STEM education proposals consider diverse forms of a pedagogical action that engage students in problem-solving and 
modelling activities, critical judgment, empowerment, and making sense of mathematical and non-mathematical practices developed in distinct cultural contexts, which involve diverse and distinct ways of thinking, reasoning, and doing and knowing mathematics.

This ethnomathematical perspective presents a proposition of a transformative pedagogical action that encourages the development of abilities that transform students into critical and reflective citizens who can make a difference in their communities in order to transform society. The relation between mathematics and cultural practices helps facilitating and consolidating student mathematical thinking and reasoning abilities because "cultural practices encourage and sustain certain kinds of cognitive processes, which then perpetuate the cultural practices" (ADENEGAN; IPINLAYE; ADEWOYE, 2016, p. 252).

It is important that school curricula apply local (emic) language, sociocultural practices, tacit knowledge, and mathematical ideas and procedures in order to make the teaching and learning processes remarkable, productive, encouraging, and rewarding (ADENEGAN; IPINLAYE; ADEWOYE, 2016). In this regard, Furuto (2016) states that there is a need for educators (global) to discover pathways that foster the students' (emic) engagement through investigating, conceptualizing, and adapting multiple approaches to learning mathematics in local and global contexts by applying an ethnomathematical perspective into the mathematics curriculum.

Consequently, Furuto (2016) affirms that ethnomathematics empowers students to be locally minded and global citizens with a sense of place. The main objective of this glocal pedagogical action is to affirm students' identities as producers of mathematical knowledge that engage them in rigorous, relevant, and contextualized mathematical tasks. This curriculum increases mathematical content and pedagogical knowledge in culturally sustaining mathematics aligned with the assumptions of STEM education.

Thus, by drawing on a student's background and community, it is necessary to acknowledge the importance of strength-based approaches in accessing diverse funds of teaching and learning experiences (BOALER, 2002) through ethnomodelling experiences. For example, in an ethnomodelling perspective, Rosa and Orey (2017b) affirm that educators need to develop a student's cultural and linguistic background because mathematical ideas, procedures, and practices are influenced by the world around them. In this regard, one of the goals of ethnomodelling is to acknowledge different mathematical systems and distinct frameworks that have been developed throughout history.

Instead of tradition imposition or knowledge colonization, it is important that educators are supported in creating conditions for students to use their backgrounds and 
diverse learning styles to create meaningful connections between local (emic) and global (etic) knowledge through cultural dynamism (dialogic) (ROSA; OREY, 2015). This approach refers to an understanding between and exchange with systems of knowledge that facilitate members of distinct cultures to exploit or adapt to the world around them This cultural dynamic enables the incorporation of culture, creativity, and human invention related to changing the world to enable the creation of new abilities and competencies.

\section{Connecting STEM Education, Ethnomathematics, Trivium Curriculum, and Ethnomodelling}

There is a need for the development of new directions for the processes of teaching and learning mathematics that result from ideas, procedures, and practices that emerge from distinct sociocultural contexts. According to this assertion, these remarkable ideas, although exceedingly difficult, clearly indicate that the new generation of scientists, engineers, and, obviously, mathematicians will need broader attitudes towards mathematics. The challenging problems require, in addition to new mathematical techniques, the training of a new generation of investigators in the mathematical sciences (D’AMBROSIO, 2012).

This context calls for the creation of new mathematical professionals who can mediate between mathematics, engineering, technologies, and applied science. This cross-fertilization of ideas is crucial for the future health of science and mathematics (GROMOV, 1998). In order to achieve realistic responses to material, social, economic, environmental, political, and spiritual needs, D'Ambrosio (2006) stated that members of distinct cultural groups have always created and generated ways, procedures, strategies, styles, arts, and techniques (techné $\rightarrow$ tics) of doing and knowing, which is related to the learning process of explaining and coping with (mathema) the natural, social, and cultural environments (ethno).

Thus, ethnomathematics is related to the analysis of the tics (arts and techniques) of mathema (explaining, understanding, dealing with) in different ethnos (natural and sociocultural environments). Thus, like STEM, ethnomathematics (ethno + mathema + tics) emerges as a transdisciplinary and transcultural research program in the history and philosophy of mathematics, with pedagogical implications. Regarding ethnomathematics research, D'Ambrosio (2006) states that knowledge construction can be considered as a threestep process based on the following questions:

- How can ad hoc practices and problem-solving be developed into methods?

- How can methods be developed into theories? 
- How can theories be developed into scientific invention?

While methods are essentially related to the rational and coordinated use of techniques; theories are impregnated modes of explanation and understanding often based on myths, spirituality, mysticism, and religions, on science, on mathematics, on ideology, and on mathematical reasoning (D’AMBROSIO, 2012).

This means that mathematical thinking is developed in different cultures in accordance with common problems that are encountered within a particular glocal-cultural context. In this regard, in order to determine solutions to specific problems: a) ad hoc solutions are created, b) generalized methods are developed from those solutions to solve similar problems, and c) theories are developed from these generalized methods.

Ad hoc practices that deal with daily problems and situations arise from reality as the result of the knowing actions. Hence, knowledge development is triggered from a reality in which "ethnomathematics is not recognized as a structured body of knowledge, but rather as a set of ad hoc practices" (D'AMBROSIO, 1997, p. 21). In this regard, both material and intellectual instruments, such as counting and measuring are responsible for the development of ad hoc solutions.

For example, D'Ambrosio (2006) affirms that western procedures and techniques originated in the evolution of ad hoc practices and solutions developed by members of distinct cultural groups, often to solve extremely local problems and needs, at the same time, some classroom actions can be developed as a result of these theoretical reflections:

$$
\text { ad hoc practices } \Rightarrow \text { methods } \Rightarrow \text { theories } \Rightarrow \text { inventions }
$$

This context allowed D'Ambrosio (2006) to provide an example of this knowledge construction process: a) an observational geometry experiment that deals with students observing solids in water ( $a d h o c)$, b) an experimental geometry activity that deals with students measuring the level of displaced water (method), c) an explanatory geometry that deals with students explaining the changes occurred in the level of water, which leads them to develop the concept of volume (theory), and d) consequently, students construct geometric solids with a given volume (invention).

According to D'Ambrosio (2006), these questions involve processes of knowledge generation and production, be it intellectual and social in organization, and its diffusion, which are normally treated in isolation, as specific disciplines, such as found in the cognitive sciences (knowledge generation), epistemology (intellectual knowledge organization), and 
history, politics, and education (social organization, institutionalization, and knowledge diffusion).

In the context of ethnomathematics, members of distinct cultural groups know mathematics in ways that are quite different from academic mathematics taught in schools (D'AMBROSIO, 2006). There is a tendency to consider these ad hoc mathematical practices as non-systematic and non-theoretical knowledge systems. In contrast, the study of ethnomathematics underlies a STEM structure of inquiry in ad hoc mathematical ideas and procedures by considering how these practices and problem-solving techniques and strategies can be developed into methods and theories.

Since different types of problems are common in different cultural groups, the kinds of solutions, methods, theories, and inventions developed often differ from culture to culture (D’AMBROSIO, 2006; ROSA; OREY, 2015). Phenomena that are recognized as a problem and a solution in one cultural context may have no meaning or value to another cultural group. Thus, it is necessary that educators recognize the need for students to gain a broader worldview of society and the mathematics it has developed overtime.

The links between an ethnomathematics, ethnomodelling, the trivium curriculum, and STEM education certainly describe the possibility for innovative pedagogical actions for all students. Thus, it is important to comprehend shifts in understanding required to help educators to learn ethnomathematics techniques as well to acquire the confidence and courage to release themselves from years of traditional or isolated thinking. To enrich its pedagogical action, the influence of ethnomathematical ideas, procedures, and practices can be integrated into the STEM and create a STEM-Trivium Curriculum.

In this pedagogical action, students are encouraged to develop projects that involve relevant themes in their own communities. For example, consumer education enables students to study mathematical content related to percentage, interest, and the monetary system (including important exchange rates). In this context, the results of the study conducted by Pinheiro and Rosa (2020a) showed that cultural traits produced by Deaf students concerning the development of their financial education are in accordance with the ethnomathematics perspective and its connection to Deaf Culture.

According to Pinheiro and Rosa (2020b), Deaf Culture is understood as the way in which Deaf people understand the world and modify it to make it accessible and habitable by adjusting to it with their own sociocultural perspective, which contributes to the definition of deaf identity and the soul of the Deaf Communities. This means that Deaf Culture covers the language, ideas, beliefs, customs, and habits of Deaf people. It is important to state here that 
the specificity of the Deaf Culture is associated with the existence of Sign Language in which jargon, slang, habits, ways of thinking, and behaviors are common sociocultural elements that help its members emphasize their own identity.

The investigators also presented a diversity of ways of signing mathematical content in Brazilian Sign Language (Libras), as well the communicative differences that arose due to the use of these sign variations in solving curricular activities related to their daily lives. Thus, ethnomathematics contributed to the understanding and awareness of the characteristics of Deaf Culture and its relations to school mathematics.

By working with the trivium curriculum, the results of the study conducted by Rosa and Raimundi (2019) showed the contribution of developing contents related to financial education grounded on an ethnomathematical perspective and in the Trivium Curriculum. The authors developed curricular activities proposed in the classrooms with the objective of developing concepts of literacy, matheracy, and technoracy.

This pedagogical action enabled the use of real-world problems in the classroom that were solved with the application of communicative, analytical, material, and technological instruments. It contributed to the students' understanding of financial education related to daily practices, such as the ability to read and interpret simple and compound interests in financing, promotions, advertisements, and Black Friday (ROSA; RAIMUNDI, 2019).

These projects help students organize mathematical content in a way that gives them power and meaning in accordance with the themes they choose to develop in their classrooms (ROSA; OREY, 2017b). This approach enables educators and students to celebrate a diversity of ways in which to make mathematics curriculum more meaningful and accessible for all students.

For example, Orey, Rosa, and Braga (2020) investigated 34 students in a public night school context. The participants' ages ranged from 18- to 33-years old and were all in the second year of high school in the Youth and Adult Education Program in the Belo Horizonte metropolitan region, the state capital of Minas Gerais, Brazil. The main objective of this study was to develop modelling as a learning environment that sought to link theory and practice by transforming a well-known street activity in Brazil called carrinhos de rolimã (roller carts) into a sport practice by restructuring teaching practices (OREY; ROSA; BRAGA, 2020). Figure 9 shows a Brazilian roller cart. 


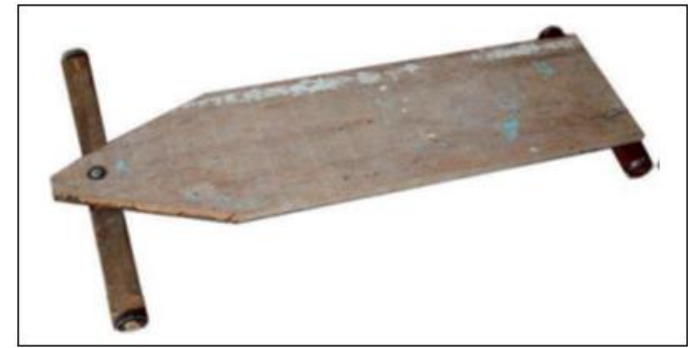

Figure 9: Brazilian roller cart

Source: Orey, Rosa and Braga (2020, p. 200)

This investigation enabled Orey, Rosa and Braga (2020) to apply the concept of educational sports engineering (BROTHWELL, 2016) in association with the elaboration of modelling tasks related to designing, building, and testing (validating) the roller carts by regulating and standardizing their dimensions. Although relatively rare internationally, Moore, Miller, Lesh, Stohlmann, and Kim (2013, p. 30) affirm that the integration of engineering concepts into mathematics curriculum "can provide great problem-solving opportunities for students to learn about mathematics, science, and technology while working through the engineering design process".

In this investigation, students analyzed collected data as well interpreted results obtained in this study in order to understand the construction and performance of competitors and their carts (OREY; ROSA; BRAGA, 2020). Hence, concerns associated with unfair competitive advantages helped in the promotion of student critical and reflective discussions related to planning and development of equipment through the exploration of sports engineering and modelling.

In this context, "students in their groups designed a model and constructed their roller carts by learning how mathematical concepts were used in the preparation, analysis, and resolution of their models. Then, students chose a standardized model of the roller cart to be used in the race competition" (OREY; ROSA; BRAGA, 2020, p. 202). Figure 10 shows the roller cart models developed by the students in each group.

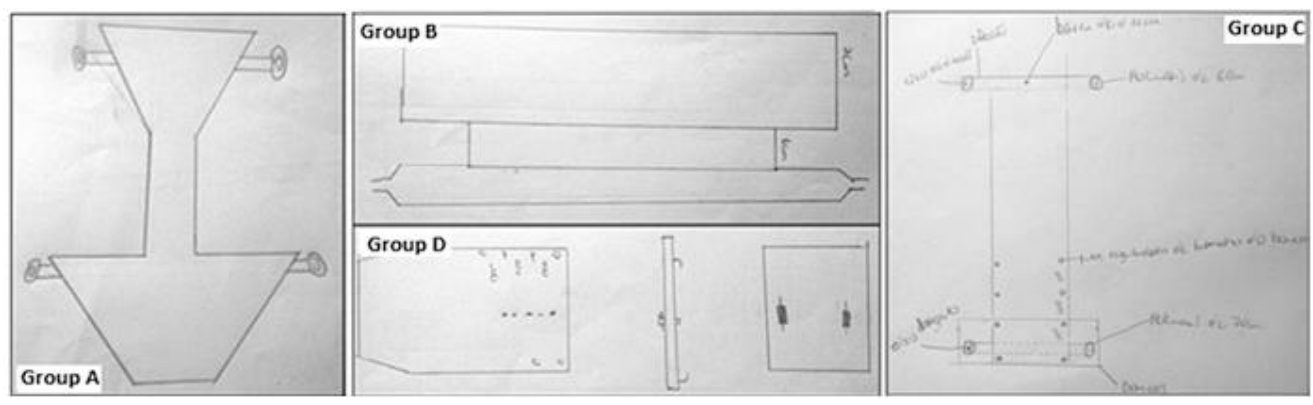

Figure 10: Roller cart models developed by the students in each group Source: Orey, Rosa and Braga (2020, p. 202) 
In this approach, Orey, Rosa and Braga (2020) stated that modelling was considered as a learning environment in which students inquired and investigated a phenomenon (model of a standardized roller cart) by working with real problems and using mathematics to understand, simplify, comprehend, explore, and solve problems, and situations in an interdisciplinary fashion through STEM Education.

In this learning environment, the trivium curriculum forms a pedagogical action that enables students to develop literacy, matheracy, and technological skills and abilities that enhance the teaching and learning processes. And, at the same time, it can contribute to the development of major changes into the mathematics curriculum (OREY; ROSA; BRAGA, 2020).

It also improves expectations for students' achievement and the role of mathematics educators in the educational enterprise though the development of STEM education as an active area of research and investigation that seek to encourage a growing recognition that mathematical knowledge is embedded in a wide range of contexts, which allows them to perceive connections between mathematics and phenomena that occur in the real world. Therefore, we emphasize that an ethno-trivium-STEM collaboration enables the development of this holistic approach.

Thereafter, Rosa and Orey (2017a) emphasize that mathematics education should enable all students to both critically and reflectively use communicative instruments, apply a diversity of analytical instruments, and become aware of the capability and inadequacy of technological instruments that are essential to exercise rights and duties necessary in the practice of citizenship.

Ethnomathematics fits this broad view of STEM Education because it is based on epistemologies and histories that focus on local knowledge regarding science, engineering, mathematics, and technological devices. Its main goal is to value and respect cultural dignity and, at the same time, prepare students for their active participation in society (ROSA; OREY, 2017a).

In relation to the school curricula, Rosa and Orey (2015) say it becomes necessary that curricular reconceptualization present innovative proposals based on the trivium curriculum, which is considered as an educational response to the expectations of eliminating inequality and violations of human dignity, which are the first steps toward social justice. Consequently, ethnomathematics, ethnomodelling, and the trivium curriculum may become important elements for applying mathematical content that requires STEM representation in mathematics education. 
Millions of students worldwide leave mathematics classrooms unsure of its value or power, or even worse, its beauty. This is as if when they learned their own native language, yet never had the opportunity to write a story or a poem. In this case, ethnomodels can be considered as mathematical poems that express how learners perceive and learn, and most importantly, feel about a given phenomenon they have modeled.

In this context, ethnomathematical knowledge shows students how mathematics is developed and used in alternative ways that they might never study in the traditional western academic experiences, as well it shows that western mathematical knowledge was developed by members of distinct cultural groups and this knowledge can help students understand problems faced by society in their own communities.

Mathematical knowledge can be incredibly powerful, both as a way of deepening their understanding of mathematics and as a cultural conduit for appreciating and valuing their own social context. It also allows for creativeness in mathematics to be manifested (ROSA; OREY, 2017a). When this objective is achieved, students gain access to meaningful curricular opportunities that promote critical thinking skills that can be applied to their academic as well as everyday lives.

In educational systems, ethnomathematics can critically and reflectively provide communicative, analytic, material, and technological opportunities that enhance STEM educational practices. Critical familiarity with these opportunities is an important objective of education. Both school/academic mathematics and ethnomathematics activities are intrinsic to the use of these instruments that can help students be fully prepared to become active and participating citizens in their communities.

A focus on a diversity of cultures, languages, creativity, and innovation is necessary for the development of all students and can guard against a sense of domination or colonialization by traditional academic sciences and mathematics. In this regard, it is necessary to engage "students in work that results in their need to learn material that is essential to their education as citizens in a democracy and to their right to claim to be well educated human beings is the primary business of schools" (SCHLECHTY, 2011, p. 8).

Historically, Rosa and Orey (2017a) stated that all societies have both absorbed and created (glocalization) what to them may be new mathematical, scientific, engineering, and technological innovations. It is important to understand the way material and intellectual innovation permeates the critical and reflective thinking of citizens. The technology component allows for a deeper understanding of science, mathematics, and engineering since 
it enables students to critically apply the learned content by using computers and other technological resources.

Both ethnomathematics and a trivium curriculum serve as bridges that enable students to perceive the interrelation of studying mathematics, engineering, technology, and science within their own cultural backgrounds. It is important to demonstrate how a given pedagogical action using aspects of ethnomathematics can be linked to the study of STEM and to the proposal for ethnomodelling and a trivium curriculum for mathematics.

\section{Final Considerations}

It is necessary to acknowledge that educational systems around the world have persistent inequities in access and in participation in STEM. This is most egregious among many students with disabilities and along many racial, socioeconomic, gender, and geographic lines. Thus, a perspective using STEM-Trivium Curriculum is important to ensure that the engagement and the success of all students and educators.

A traditional sense of rigor or elitism in regard to access to distinct educational systems around the world perpetuate deterministic views of genetics or stereotypic ideas of culture and fails to recognize the benefit of STEM education in promoting higher level critical thinking skills and lifelong civic engagement, regardless of students' post-secondary plans and career aspirations (VOLMERT et al., 2013).

These disparities have threatened the ability to close gaps in education and poverty, to meet the demands of many technology-driven economies, to ensure national securities, and to maintain preeminence in mathematical and scientific research and technological innovation. It is important to state here that a STEM-Trivium Curriculum plays an important role in reducing these inequities.

In this context, policies and practices that ensure equitable access to the best teaching and learning practices are not universally widespread. For example, countries, states, school districts, and schools are struggling to provide students with experiences required for the development of educational abilities.

Many federal, state, regional, and local school leaders struggle to close persistent achievement gaps in core subjects such as mathematics and science (ROSA; OREY, 2017a). In our experience, many school districts around the world are challenged to promote the widespread adoption of emerging best practices that encourage the participation of historically underrepresented students in career and technical educational programs. Most universities and 
other higher education institutions rarely have the same racial, ethnic, social make-up as the wider communities in which they reside.

A STEM-based program for developing a more equitable mathematics curriculum needs to propose "pedagogical action that deals with problem solving, modelling, critical judgment, and making sense of mathematical and non-mathematical contexts, which involve distinct ways of thinking, reasoning, and knowing mathematics and its uses in practical contexts" (ROSA; OREY, 2015, p. 597).

An ethnomathematics-based curriculum assists to develop and integrate appropriate STEM experiences into early childhood education and equitably engaging students: a) with disabilities, b) from low-income households, c) from rural areas, d) from racial and ethnic minority groups, and e) females in STEM subjects (ROSA; OREY, 2017a).

This context allows educators to provide support to help students build "knowledge of the nature and history of science, mathematics, and technology, an understanding of common themes that cut across the disciplines, and the development of scientific habits of mind as essential aspects of science literacy” (KESIDOU; KOPPAL, 2004, p. 5).

The development of STEM must be "framed in terms of improving participation in basic education and putting in place a qualified teaching workforce; and issues of socioeconomic equity and building human capital in previously excluded populations have greatest resonance" (MARGINSON et al., 2013, p. 57).In this regard, Rosa and Orey (2017b) state that the combination of formal and informal types of education is a useful tool for looking at STEM because it can be adapted to different and equally important pedagogical actions.

1. First, the formal environment ensures students an unrestricted education, allowing everyone to have access and share school content and ideas.

2. Second, the informal environment plays a complementary role by using the previously established knowledge in formal education to offer student contexts for greater autonomy.

There is a need to verify how to explicitly find and then use student emic knowledge to draw experiences from the communities they live in, and to build their understanding on a foundation of culture-based mathematics and science. Student attitudes may change in relation to mathematics when activities are task-oriented and related more closely to their own lives. Therefore, ethnomathematics-based pedagogical actions diminish students' mathematics avoidance and help them experience the connections between science, mathematics, engineering, and technology with personal experience and cultural heritage (ROSA; OREY, 
2015).

This form of STEM encourages alternative spheres of socioeconomic status, ethnicity, culture, and linguistic differences to come together and examine the mathematics, technology, science, and engineering produced and used by members of distinct cultural groups. It suggests an educational alternative for students who are more likely to become marginalized during traditional school experience, this is especially widespread regarding mathematics.

This marginalization is manifested as a lack of interest in mathematical activities, low performance in mathematics classes, and underrepresentation in science related careers (BUXTON; LEE, 2010). In order to address activities to increase equity and quality activities, STEM disciplines need to be explored to design and implement lessons and activities founded in the ethnic, historical, social, and cultural diversity around the world.

Recognizing the importance of nurturing STEM abilities needed to compete in today's glocalized world, it is necessary to explore innovative ways in which to teach mathematics and science in more engaging ways. As we have shown here, an ethno-trivium-STEM consideration can ameliorate this to some extent.

It is important that educational leaders promote full use of human resources in mathematics, science, engineering, and technology to ensure the development and use of the talents, abilities, and skills across a wide diversity of distinct ethnic, racial, and economic backgrounds of learners. Thus, it is necessary to guide public school leaders to support educators to develop methods that motivate and spark interest in the process of learning STEM-related subjects.

Diverse pedagogical experiences aimed towards the development of ethnomathematics, ethnomodelling, and the trivium curriculum offer ways of improving students' mathematics learning by using STEM. These experiences help them perform mathematics in a contextualized, holistic, and meaningful context. For example, Rosa (2010) states that this pedagogical action calls for high quality learning while helping students to develop a sense of consciousness that is critical and reflective in their thinking.

In the trivium curriculum proposal, we have shown how literacy (communicative instruments) is the capacity that students must use to process information present in their daily lives; matheracy (analytical instruments) is the capacity students must develop to interpret and analyze signs and codes in order to propose models to find solutions for problems they face daily; and technoracy (material and technological instruments) is the capacity students must use to combine different instruments that help them to solve these problems (D'AMBROSIO, 1999). 
STEM effectively transforms the typical teacher-centered classroom by encouraging the development and elaboration of lessons that are driven by problem-solving, and discovery. This exploratory learning approach requires students to actively engage in finding the solutions for the problems faced in their own lives. By implementing STEM-Trivium Curriculum, educators can motivate learners in learning to think about mathematical, engineering, technological, and scientific knowledge in different modes and contexts.

If an important objective of STEM is to prepare students to tackle problems and situations present in their daily life, then the combination of instruments found in the Trivium Curriculum for mathematics uses an ethnomathematical perspective that is essential for the development of student criticism and reflectiveness. This curriculum is an interdisciplinary approach that provides relevant learning experiences for all students that exceeds the mere transference or banking of knowledge. Helping educators foster student engagement through the development of mathematical competencies in their own communities is vital.

STEM Education coupled with an ethnomathematical perspective and developed with the Trivium Curriculum can be considered as an interdisciplinary approach to learning where academic concepts are linked with real-world applications and activities performed by students in their daily lives. This means that the students apply science, technology, engineering, and mathematics in distinct contexts that make connections between the classrooms, the world around them, and the sociocultural environment in which they live in.

This approach alerts investigators and educators about cultural aspects of literacy, matheracy, and technoracy rooted in the community that can be worked into the mathematics classrooms in order to create a sense of mathematical interest and relevancy in the students. Finally, because it presents us with a social consciousness reflection in individual cultural practices, the Trivium Curriculum in an ethnomathematical perspective is an important element of STEM Education.

In this regard, different contexts require different numeracy skills, abilities, and competencies that can be developed and activated by the students because it promotes the discovery and analysis of processes related to the origin, transmission, diffusion, and institutionalization of mathematical knowledge acquired in a diversity of cultural environments and in an interdisciplinary fashion.

Creating innovative pedagogical actions that embrace multiple levels of the curriculum is vital, indeed necessary, for students to embrace a path that is continually moving from a scientific perspective to a mathematical conceptualization and flows into scientific, engineering and technological careers. Thus, educators need to be supported in proposing the 
development and implementation of ethnomodelling and a trivium curriculum for STEM education based on the principles of the ethnomathematics.

Because it emphasizes the social justice aspects and the sociocultural diversity of mathematics, ethnomathematics is overarching. Within ethnomathematics is ethnomodelling that explains, models, and represents local, global, and glocal mathematical ways of thinking and reasoning. It is linked to engineering, mathematics, science, and technology, which are the pillars of STEM education. Ethnomathematics is the bridge.

\section{References}

ADENEGAN, K. E.; IPINLAYE, A. B.; ADEWOYE, R. A. Ethnomathematics and indigenous mathematics: implications for science technology engineering and education. Science \& Technology, Washington City, v. 2, n. 6, p. 251-256, 2016.

ANDERSSON, A.; NORÉN, E. Agency in mathematics education. In: PYTLAK, M.; ROWLAND, T.; SWOBODA, E. (Eds.). Proceedings of the Seventh Congress of the European Society for Research in Mathematics Education - CERME VII. Rzeszów: University mathematics of Rzeszów, 2011. p. 1389-1398.

BOALER, J. Paying the Price for sugar and spice: shifting the analytical lens in equity research. Mathematical Thinking and Learning, Abingdon-on-Thames, v. 4, n. 2-3, p. 127-144, 2002.

BROTHWELL, A. What is sports engineering. Sheffield: ISEA, 2016.

BUCHANAN, R. A. History of technology. Encyclopædia Britannica. London: Britannica Group, 2019.

BUXTON, C.; LEE, O. Diversity and equity in science education: New York: Teachers College Press, 2010.

BYBEE, R. W. Advancing STEM education: a 2020 vision. Technology and Engineering Teacher, Reston, v. 70, p. 30-35, 2010.

CHIU, A.; PRICE, A. C.; OVRAHIM, E. Supporting elementary and middle school STEM education. Chicago: Museum of Science and Industry, 2015.

CHUBIN, D. E.; MALCOM, S. M. Making a case for diversity in STEM fields. Inside Higher Education, Washington City, v. 1, n. 1, p. 1-4, oct. 2008.

CORTES, D. P. O.; OREY, D. C. Connecting ethnomathematics and modelling: a mixed methods study to understand the dialogic approach of ethnomodelling. Revemop, Ouro Preto, v. 2, n. 2, p. 1$25,2020$.

D'AMBROSIO, U. Ethnomathematics and its place in the history and pedagogy of mathematics. In: POWELL, A. B.; FRANKENSTEIN, M. (Eds.). Ethnomathematics: challenging eurocentrism in mathematics education. Albany: State University of New York Press, 1997. p. 13-24.

D'AMBROSIO, U. Literacy, matheracy, and technoracy: a trivium for today. Mathematical

Thinking and Learning, Abingdon-on-Thames, v. 1, n. 2, p. 131-153, 1999. 
D'AMBROSIO, U. The program ethnomathematics and the challenges of globalization.

Circumscribere, São Paulo, v. 1, p. 74-82, 2006.

D’AmbrosiO, U. Peace, social justice and ethnomathematics. The Montana Mathematics Enthusiast, Missoula, v. 1, p. 25-34, 2007.

D'AMBROSIO, U. A broad concept of social justice. In: WAGER, A. A.; STINSON, D.W. (Eds.).

Teaching mathematics for social justice: conversation with educators. Reston: NCTM, 2012. p. 201 213.

D'AMBROSIO, U. Change in space, urban culture and ethnomathematics. In: BABACI-WILHITE, Z. (ed.). Human rights in language and STEM Education. Rotterdam: Sense Publishers, 2016. p. 207 219.

D’AMBROSIO, U. Etnomatemática, justiça social e sustentabilidade. Estudos Avançados, São Paulo, v. 32, n. 94, p. 189-204, 2018.

EGLASH, R.; BENNETT, A.; O’DONNELL, C.; JENNINGS, S.; CINTORINO, M. Culturally situated designed tools: ethnocomputing from field site to classroom. American Anthropologist, Bethesda, v. 108, n. 2, p. 347-362, jun. 2006.

ELAINE, J. H. What is STEM Education? New York: Beta Live Science, 2014.

ENGLISH, L. D.; HUDSON, P. B.; DAWES, L. A. Engineering based problem solving in the middle school: design and construction with simple machines. Journal of Pre-College Engineering Education Research, West Lafayette, v. 3, n. 2, p. 1-13, 2013.

FRITZ, D. W.; STRONG, D. S.; BRYANT, J. T. Ancestral engineering: towards the integration of archaeology and engineering. Conference Proceedings of the Second Annual Conference of the Canadian Engineering Education Association (CEEA). Winnipeg: University of Manitoba, p. 1-5, 2007.

FURUTO, L. H. L. Pacific ethnomathematics: pedagogy and practices in mathematics education. Teaching Mathematics and its Application, Oxford, v. 33, n. 2, p. 110-121, 2014.

FURUTO, L. Lessons learned: strengths-based approaches to mathematics education in the Pacific. Journal of Mathematics and Culture, Toledo, v. 10, n. 2, p. 55-72, 2016.

GATES, S. J.; MIRKIN, C. Encouraging STEM students is in the national interest. Washington City: The Chronicle of Higher Education, 2012.

GLOVER, E. The myth of accountability. Lanham: Rowman \& Littlefield Education, 2013.

GONZALEZ, H.; KUENZI, J. Science, technology, engineering, and mathematics (STEM) education: a primer. Washington City: Library of Congress - Congressional Research Service, 2012.

GROMOV, M. Possible trends in mathematics in the coming decades. Notices of the American Mathematical Society - AMS, Providence, v. 45, n. 7, p. 846-847, 1998.

HANSSON, S. O. Technology and mathematics. Philosophy \& Technology, New York, v. 33, p. 117-139, 2019.

KESIDOU, S.; KOPPAL, M. Supporting Goals-Based Learning with STEM Outreach. Journal of STEM Education: Innovations and Research, Auburn, v. 5, n. 3-4, p. 5-12, 2004. 
LANTZ, H. B. Science, technology, engineering, and mathematics (STEM) education: what form? what function? Charlotte: SEEN Southeast Network, 2009. Disponível em:

https://dornsife.usc.edu/assets/sites/1/docs/jep/STEMEducationArticle.pdf. Acesso em: 17 mai. 2020.

LAUBIN, R.; LAUBIN, G. The indian tipi, its history, construction and use. Norman: University of Oklahoma Press, 1989.

MARGINSON, S.; TYTLER, R.; FREEMAN, B.; ROBERTS, K. STEM: country comparisons. Report for the Australian Council of Learned Academies. Melbourne: Australian Council of Learned Academies, 2013.

MARKHAM, T. Project-based learning. Teacher Librarian, Chicago, v. 39, n. 2, p. 38-42, 2011.

MOON, J.; SINGER, S. R. Bringing STEM into focus. Education Week, Bethesda, v. 31, n. 9, p. 24$32,2012$.

MOORE, T. J.; MILLER, R. L.; LESH, R. A.; STOHLMANN, M. S.; KIM, Y. R. Modeling in engineering: the role of representational fluency in students' conceptual understanding. Journal of Engineering Education, New York, v. 102, n. 1, p. 141-178, 2013.

NGA. Building a science, technology, engineering and math agenda: an update of state actions. New York: National Governors Association, 2011.

NRC. STEM integration in K-12 education: status, prospects, and an agenda for research. National Research Council. Washington City: The National Academy Press, 2014.

OREY, D. C. The ethnomathematics of the Sioux tipi and cone. In: SELIN, H. (Ed.). Mathematics across culture: the history of non-western mathematics. Dordrecht: Kluwer Academic Publishers, 2000. p. 239-252.

OREY, D. C.; ROSA, M. Explorando a abordagem dialógica da etnomodelagem: traduzindo conhecimentos matemáticos local e global em uma perspectiva sociocultural. Revista

Latinoamericana de Etnomatemática, Pasto, v. 11, n. 1, p. 179-210, 2018.

OREY, D. C.; ROSA, M.; BRAGA, R. S. Mathematical modelling as a learning environment to transform a street activity into a sport practice. In: STILLMAN. G. A.; KAISER, G.; LAMPEN, C. E. (Eds.). Mathematical modelling education and sense-making. Cham: Springer, 2020. p. 199-209.

PEA, R. D. Cognitive technologies for mathematics education. New York: Center for Children and Technology, 1986.

PINHEIRO, R. C.; ROSA, M. R. Ethnomathematical paths to financial education: analysing cultural traits of Deaf students. Revemop, Ouro Preto, v. 2, n. 2, p. 1-18, 2020 a.

PINHEIRO, R. C.; ROSA, M. R. Intertwining the ethnomathematics and the deaf culture to promote financial education for deaf students. In: ROSA, M.; OLIVERIA, C. C. (Eds.). Ethnomathematics in actions: mathematical practices in Brazilian indigenous, urban, and afro communities. Cham: Springer, 2020b. p. 141-160.

ROEHRIG, G. H.; MOORE, T. J.; WANG, H. H.; PARK, M. S. Is adding the E enough?: investigating the impact of K-12 engineering standards on the implementation of STEM Integration. School Science and Mathematics, Hoboken, v. 112, n. 1, p. 31-44, 2012. 
ROSA, M. The perceptions of high school leaders about English language Learners (ELL): the case of mathematics. 2010. Tese (Doutorado em Educação: Liderança Educacional) - College of Education, California State University, Sacramento, 2010.

ROSA, M.; OREY, D. C. Ethnomodeling: a pedagogical action for uncovering ethnomathematical practices. Journal of Mathematical Modelling and Application, Blumenau, v. 1, n. 3, p. 58-67, 2010.

ROSA, M.; OREY, D. C. A trivium curriculum for mathematics based on literacy, matheracy, and technoracy: an ethnomathematics perspective. ZDM, Berlin, v. 47, n, 4, p. 587-598, 2015.

ROSA, M.; OREY, D. C. Ethnomodelling: exploring glocalization in the contexts of local (emic) and global (etic) knowledges. International Journal for Research in Mathematics Education, Brasília, v. 6, n. 1, p. 196-218, 2016 a.

ROSA, M.; OREY, D. C. Humanizing mathematics through ethnomodelling. Journal of Humanistic Mathematics, Claremont, v. 6, n, 3, p. 3-22, $2016 \mathrm{~b}$.

ROSA, M.; OREY, D. C. STEM education in the Brazilian context: an ethnomathematical perspective. In: JORGENSEN, R.; LARKIN, K. (Eds.). STEM education in the junior secondary: the state of play. Cham: Springer, 2017a. p. 221-247.

ROSA, M.; OREY, D. C. Etnomodelagem: a arte de traduzir práticas matemáticas locais. São Paulo: Editora Livraria da Física, 2017b.

ROSA, M., OREY, D. C. Ethnomodelling as the mathematization of cultural practices. In: STILLMAN, G.; BLUM, W.; KAISER, G. (Ed.). Mathematical modelling and applications: crossing and researching boundaries in mathematics education. Cham: Springer, 2017c. p. 153-162.

ROSA, M.; RAIMUNDI, M. P. V. Uma abordagem etnomatemática para o currículo trivium. Revemop, Ouro Preto, v. 1, n. 1, p. 62-84, 2019.

ROTHERHAM, A.; WILLINGHAM, D. 21 st century skills: the challenges ahead. Educational Leadership, Alexandria, v. 67, n. 1, p. 16-21, 2009.

SCHLECHTY, P. C. Engaging students: the next level of working on the work. San Francisco: Jossey-Bass, 2011.

SHARMA, T.; OREY, D. C. Meaningful mathematics through the use of cultural artifacts. In: ROSA, M.; SHIRLEY, L.; GAVARRETE, M. E.; ALANGUI, W. V. (Eds.). Ethnomathematics and its diverse approaches for mathematics education. Cham: Springer, 2017.p. 153-182.

SHOCKEY, T.; MITCHELL J. B. An ethnomodel of a Penobscot lodge. In: ROSA, M.; SHIRLEY, L.; GAVARRETE M.; ALANGUI, W. (Eds.). Ethnomathematics and its diverse approaches for mathematics education. Cham: Springer, 2017. p. 257-281.

STEPHENSON, N. Introduction to inquiry based learning. Teach Inquiry. Round Rock: Education Solution, 2012.

TING-TOOMEY, S.; CHUNG, L. C. Understanding intercultural communication. Los Angeles,: Roxbury Publishing Company, 2005.

VOLMERT, A.; BARAN, M.; KENDALL-TAYLOR, N.; O'NEIL, M. You have to have the basics down really well: mapping the gaps between expert and public understanding of STEM learning. Washington City: Frame Works Institute, 2013. 
WILLINGHAM, D. T. Is it true that some people just can't do math? American Educator, Washington City, v. 33, n. 4, p. 14-19, 2009.

ZHAO, Y. Catching up or leading the way. Alexandria: ASCD, 2010.

Submetido em 02 de Junho de 2019. Aprovado em 08 de Março de 2021. 